\title{
Wood morphology and properties from molecular perspectives
}

\author{
Lennart Salmén
}

Received: 24 March 2014 / Accepted: 23 June 2014 / Published online: 4 July 2014

(C) INRA and Springer-Verlag France 2014. This article is published with open access at Springerlink.com

\begin{abstract}
- Background It is with increasing interest that wood materials are now being considered as a green resource. For improving the product performance of wood derived materials new ways of separating them from wood are required. Thus, there is a great demand for a better understanding of the ultrastructure of wood and how the components are interaction on a molecular level in building up its properties.

- Material and method By the use of microscopic and spectroscopic techniques combined with mechanical forces, new knowledge regarding especially the role of the matrix polymers, the hemicelluloses and lignin, has been gained. This relates specifically to molecular interaction and orientation.

- Results It is here demonstrated that all of the wood polymers within the secondary cell wall exhibit a preferred orientation along the fibrils. The degree of orientation decreases in the order cellulose, hemicelluloses to the lignin which only shows a small degree of orientation, probably induced by structural constrains.

- Conclusion This orientation distribution is probably what has to be considered to better predict transverse cell wall properties. Moisture accessible regions are also aligned in a parallel arrangement in the cellulose fibrils explaining its high moisture resistance. The lignin is surprisingly inactive in the stress transfer in the secondary wall. This could perhaps be related to the function of lignin providing compressive,
\end{abstract}

\section{Handling Editor: Jean-Michel Leban}

Key message "It is demonstrated that in the wood cell wall all of the wood polymers show an orientation in parallel with the fibrils, decreasing in the order; cellulose, hemicelluloses and lignin. In loading the cell wall lignin only contributes by exerting a hydrostatic pressure in the lenticular fibrillar network."

\section{Salmén $(\bowtie)$}

Business area Biorefining, Innventia, Box 5604,

SE-11486 Stockholm, Sweden

e-mail: lennart.salmen@innventia.com hydrostatic resistance in the lenticular spaces between fibrils, when longitudinally straining the fibre. This knowledge of the ultrastructural properties of the wood polymers, here presented, provides for a better understanding of the cell wall properties.

Keywords Cell wall $\cdot$ Hemicelluloses $\cdot$ Lignin $\cdot$ Mechanical properties $\cdot$ Moisture $\cdot$ Ultrastructure

\section{Introduction}

Wood is one of the most abundant biomaterials on earth. For millions of years, trees have adapted to their environment to withstand incredibly diverse conditions, while the basic function of a tree trunk is to act as a strong supporting material and to serve as a transport mechanism and a store for the nutrients of the living tree. In the structural build-up of the fibres, the tree has developed adaptive functions to deal with a variety of conditions, such as the differentiation into different forms of reaction wood. On the cell wall level, its structural arrangement serves as a material that is both strong and ductile under conditions from low to high temperatures, with moisture being present in its system. The arrangement is such, that the properties that exist in different directions are maximized so that they meet the requirements of the tree, while having the ability to adapt to a changing environment without adversely affecting the long-term performance of the structure. This ability of the wood structure to withstand harsh changing conditions presents difficulties in making use of the wood material, when trying to break down its fibres in order to extract its different building components.

There is an increasing interest today in utilizing the building blocks of the wood fibre wall as a resource, not only for energy production but also for new materials, in a desire to replace fossil fuel-based products. In utilizing cellulose as a 
raw material for textiles and films, wood-based derivatives are in great demand. There is also large interest in the possible utilization of hemicelluloses as barrier films and of lignin as an inexpensive raw material source for carbon fibre production. To separate these constituents in an economically feasible way, with good property performance, however requires a deeper understanding of the structural features of the cell wall and its organization.

\section{Cell wall anisotropy}

It is well known that the arrangement of the cellulose fibrils makes up for a highly anisotropic structure of the fibre wall, see Fig. 1. Thus, in general, the longitudinal elastic and strength properties highly exceed those in the transverse directions. However, with the minor layers of the $S_{1}$ and $S_{3}$ walls having fibrils at high angles, the cell wall possesses a high level of resistance to tubular pressure. With the cross-ply laminate that the double cell wall provides, the wood structure is amazingly adaptive to its environment. Thus, the relative decrease in cell wall properties with temperature or moisture is more or less independent of its composition (Ehrnrooth and Kolseth 1986) and fibrillar angle (MFA) (Salmén 2004) in a normal range of MFAs. This provides for a high level of durability in the wood structure in terms of how well it withstands seasonal changes.

Our understanding of the structural organization of the wood polymers in different cell wall layers has, nevertheless, still not been fully revealed on the ultrastructural level (Salmén 2004, 2005). This becomes clearly evident when trying to model wood properties based on an understanding of the polymer properties and their ultrastructural arrangement. Although the properties in the longitudinal direction, including the effects of moisture softening, have been captured very well (Bergander and Salmén 2002; Salmén 2004),

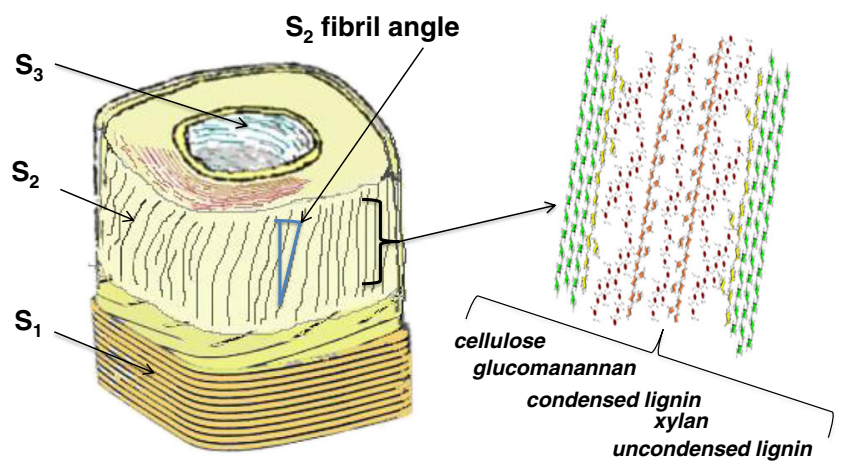

Fig. 1 Cell wall structure indicating the arrangement of the different wood polymers in the $\mathrm{S}_{2}$ wall of softwood fibres. Glucomannan is closely associated with the cellulose fibrils and the uncondensed lignin, while xylan is associated more with the condensed lignin (Ruel and Joseleau 2005; Salmén 2005) the properties across the fibre axis differ considerably when compared to experimental measurements. A refinement of the cell wall structure, achieved by introducing transition layers between the $S_{1}$ and $S_{2}$ walls, shows a somewhat improved approximation of the properties in the longitudinal direction (Wang et al. 2013, 2014), although the discrepancy between measured and calculated properties in the transverse fibre direction is still big, as is evident in Fig. 2. In the transverse direction, the properties of the in situ matrix polymers have a greater impact; they add to this uncertainty, since data about their in situ properties are still lacking.

One factor to consider is, therefore, the actual orientation of the different wood polymers within the major cell wall (the $\mathrm{S}_{2}$ wall) of the fibres. This organization should also be understood in relation to the formation of the cell wall during growth. During the process of cell wall formation, the hemicelluloses are deposited simultaneously with the organization of the cellulose microfibrils (Atalla et al. 1993; Terashima et al. 2009). Hence, it has been shown that there is a high degree of association and orientation of the hemicellulose polymers in parallel to the cellulose microfibrils (Page 1976; Åkerholm and Salmén 2001; Stevanic and Salmén 2009; Simonović et al. 2011; Salmén et al. 2012). However, although the hemicelluloses are oriented similarly to the cellulose fibrils, they show a much lower degree of orientation than that of cellulose (Salmén et al. 2012), see Fig. 3. This may not be so surprising, since the cellulose crystallises directly out from the rosette formations, while the hemicelluloses are deposited afterwards. The degree of orientation that has been measured will clearly imply that the hemicelluloses display anisotropic properties.

In much of the previous literature, it has been assumed that lignin is organized in an isotropic structure, i.e. it has the same

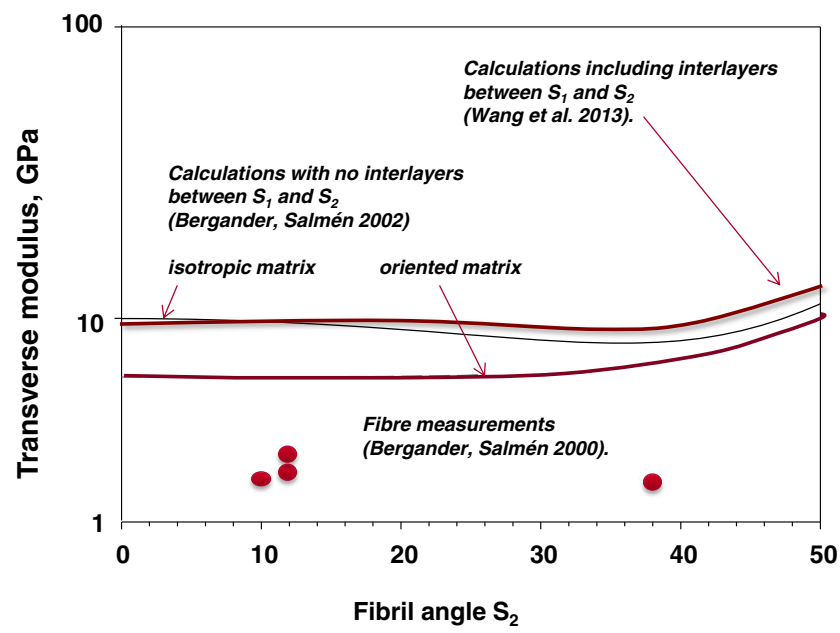

Fig. 2 The fibre transverse elastic modulus as a function of the cellulose fibril angle in the $\mathrm{S}_{2}$ layer, showing the effect of matrix polymer orientation (Bergander and Salmén 2002) and cell wall interlayer structure (Wang et al. 2013), compared to experimental data (Bergander and Salmén 2000) 


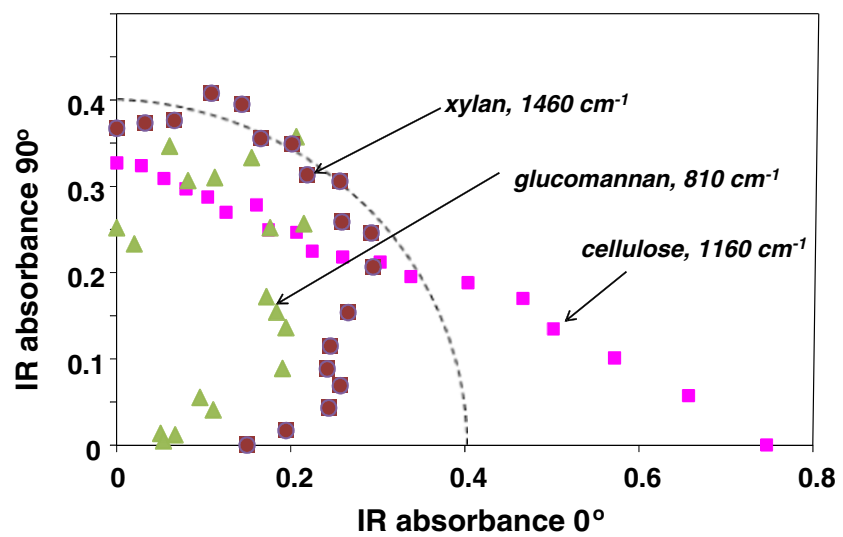

Fig. 3 Polar graph $\left(0^{\circ}\right.$ to $\left.90^{\circ}\right)$ of the absolute absorbance of xylan-, glucomannan- and cellulose-specific peaks in spruce wood fibres (Salmén et al. 2012). The cellulose $1,160 \mathrm{~cm}^{-1}$ peak is oriented along the molecule while the $1,460 \mathrm{~cm}^{-1}$ xylan peak and the $810 \mathrm{~cm}^{-1}$ glucomannan peaks are oriented transversely to the polymer chains. In the latter case, a higher absorption in the $90^{\circ}$ direction than in the $0^{\circ}$ direction indicates a polymer orientation at $0^{\circ}$. The dotted line indicates the case of a completely isotropic orientation

properties in all directions (Mark 1967). However, considering the deposition of lignin in spaces remaining in the cell wall, when cellulose and hemicelluloses have already been structured into a lenticular porous arrangement (Boyd 1982), it may be expected that this structure will impose or restrict its organization (Terashima 1990; Jurasek 1998). Indeed, Atalla and Agarwal (1985) demonstrated that the lignin aromatic ring shows an orientation parallel to the cell wall surface, i.e. in the tangential direction of the fibre wall. Recent measurements indicate that the lignin in the secondary wall could show some degree of orientation in the longitudinal fibre direction, though not to the same degree as that of the carbohydrates (Åkerholm and Salmén 2003; Stevanic and Salmén 2009; Olsson et al. 2011; Simonović et al. 2011; Salmén et al. 2012). Accordingly, lignin may also be considered to show anisotropic properties in the $S_{2}$ wall. In contrast to this arrangement, it is not surprising that, when examining the orientation of the lignin in the middle lamella region, which poses no structural restrictions, no lignin orientation is detected whatsoever, see Fig. 4 (Salmén et al. 2012). This middle lamella lignin is presumably formed without constraints from the surrounding structure and will more or less resemble a self-organized structure of lignin.

\section{Cellulose properties}

The structure of the cellulose in the cell wall is very much governed by the biological process creating a cellulose structure, which is not thermodynamically the most stable one. Clearly, the formation of cellulose fibrils by rosettes in the cell wall and the subsequent immediate formation of the partly crystalline fibril triggered by the presence of hemicelluloses

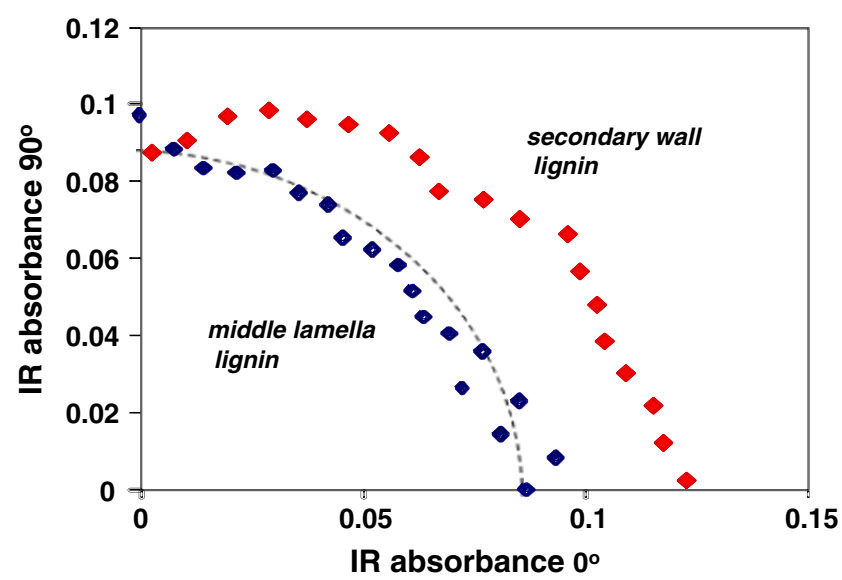

Fig. 4 Polar graph $\left(0^{\circ}\right.$ to $\left.90^{\circ}\right)$ of the absorbance $\left(1,508 \mathrm{~cm}^{-1}\right)$ of middle lamella lignin and secondary wall lignin (Salmén et al. 2012). The secondary wall lignin shows a small degree of orientation while the middle lamella lignin is completely isotropic. The dotted line indicates the case of a completely isotropic orientation

(galactoglucomannans of conifers) are important (Terashima et al. 1993). By means of this process, a 3 to $4 \mathrm{~nm}^{2}$ fibril structure of cellulose I is formed. These individual fibrils are then further assembled into aggregates (Larsson et al. 1997; Wickholm et al. 1998) with a broad size distribution up to approximately $30 \mathrm{~nm}$ in width (Bardage et al. 2004), while possessing a lenticular structure (Boyd 1982). The surfaces of all these fibril assemblies are probably still covered with glucomannan, while the remaining spaces are successively filled out with a matrix of xylan and lignin (Terashima et al. 2009).

Although carbohydrates are highly hygroscopic, an increase in moisture content does not make a big impact on the mechanical properties of the fibre (Salmén 2004). It is well known that moisture cannot access the crystalline regions of the cellulose, which is why the structural arrangement of these in the fibril structure must be of great importance. Molecular deformation studies (Salmén and Bergström 2009) clearly showed that the hygroscopically accessible regions of the carbohydrates are mostly arranged in a parallel arrangement with the cellulose crystalline areas, see Fig. 5. Most of the accessible regions exist on the surfaces of the fibrils. Possible disordered, moisture accessible, regions are probably spread out along different fibrils in such an arrangement that they are overlapped by crystalline regions within the cellulose aggregate. This explains why a three decade decrease in the stiffness of accessible carbohydrates is only evident as a $10 \%$ reduction in the longitudinal stiffness of wood fibres (Salmén 2004).

During the pulping process, it is well known that a further increase in cellulose fibril aggregation occurs as a consequence of a loss of restricting spacers among the fibrils (Duchesne and Daniel 2000; Duchesne et al. 2001; Hult 2001; Hult et al. 2001; Molin 2002; Fahlén and Salmén 


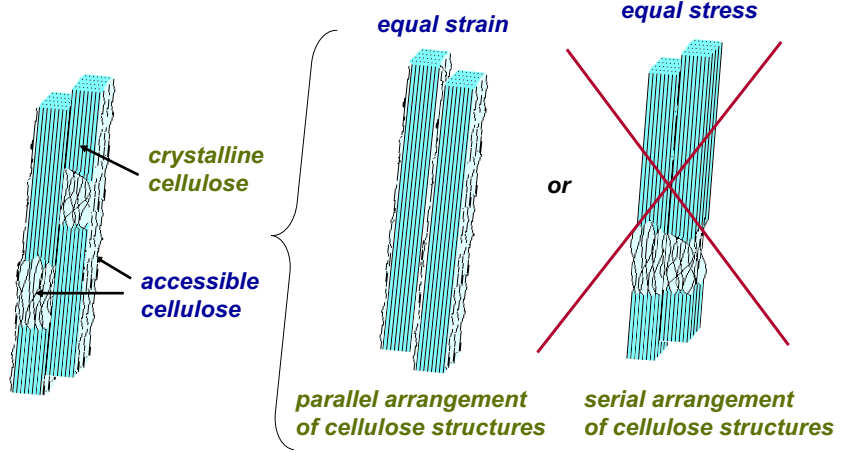

Fig. 5 Cellulose fibril structure indicating the distribution of crystalline and moisture accessible cellulose regions. The structure may be viewed as either a parallel arrangement of crystalline and accessible regions, representing an equal strain situation, or a serial arrangement of the components, representing an equal stress situation. Molecular deformation studies using FTIR indicated the former arrangement as dominating in wood and cellulose fibres (Salmén and Bergström 2009)

2003). The softening of the components that occurs at high pulping temperatures also diminishes restrictions to an aggregation of the free cellulose surfaces, which is diagrammatically shown in Fig. 6 (Fahlén and Salmén 2003). Hence, the extent of aggregation is dependent on the hemicelluloses that are removed (Salmén 2005), on the extent of the removal and on the thermal conditions during such processes.

In terms of cellulose processing, a desirable condition is to have as large as possible a specific surface area, meaning that there should be an attempt to achieve the smallest average size of the cellulose aggregate. Therefore, since the cellulose aggregation that occurs during pulping leads to a less accessible cellulose component, i.e. cellulose with a reduced specific surface area, this would be undesirable in respect to the disassembly of the fibre structure into valuable bioproducts. Furthermore, the strength properties of pulp fibres are affected negatively, resulting in lower tear properties, due to an increase in the size of cellulose aggregates (Larsson and Salmén 2014).
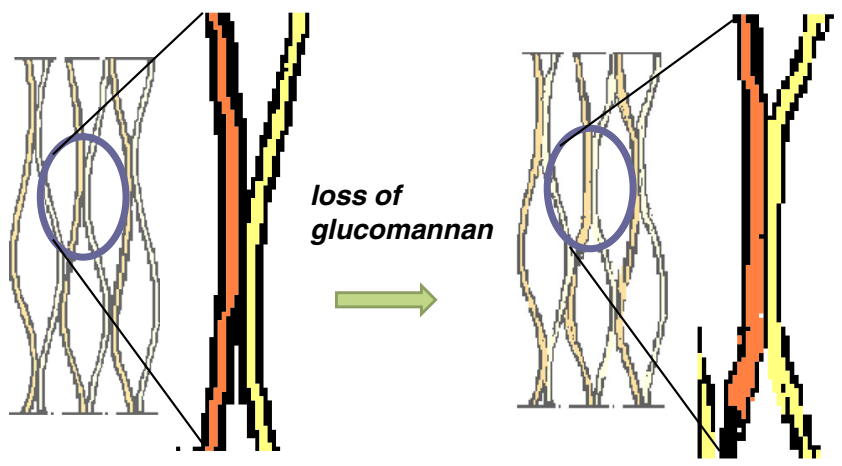

Fig. 6 Cellulose aggregate structure indicating the increase in size of a cellulose aggregate resulting from the extraction of glucomannan. The increased size is the result of a larger area of contact among aggregates/ fibrils, enabling, on average, larger aggregates to be viewed in cross sections

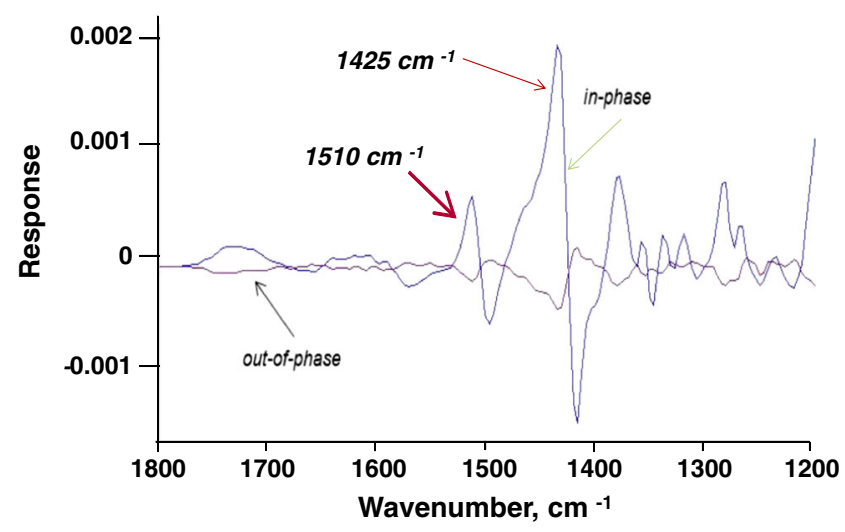

Fig. 7 Dynamic FTIR spectra of peeled fines (primary wall) from mechanical pulp fibres, showing the in-phase and out-of-phase components as a function of the wavenumber in the interval 1,800 to $1,200 \mathrm{~cm}^{-1}$ at an $\mathrm{RH}$ of $0 \%$ and at $25{ }^{\circ} \mathrm{C}$. The split peak of the cellulose $\mathrm{C}-\mathrm{OH}$ bending vibration at $1,425 \mathrm{~cm}^{-1}$ reflects the straining of cellulose, while the split peak of the lignin aromatic ring at $1,510 \mathrm{~cm}^{-1}$ indicates the stress contribution from lignin

\section{Lignin properties}

Lignin plays an essential role in the structural assembly of a cell wall (Terashima et al. 2009). Lignin is generally considered to provide resistance to compressive forces in the structure, as exemplified by its increasing concentration in "compression wood", where the tree reacts by increasing its capacity to withstand greater compressive forces. Owing to the somewhat lower hydrophilicity of lignin, when compared to carbohydrates, it is also likely that it contributes to the water resistance of the structure, serving to keep the cell wall as an integrated structure. The extent to which lignin interacts in a mechanical sense with the other wood components has still not been fully explained. The existence of covalent bonds between the lignin and hemicelluloses (LCCs) has long been debated, but their presence in wood seems clear, at least to a certain extent (Lawoko et al. 2005), although an increase in these bonds may be expected to occur during pulping (Iversen

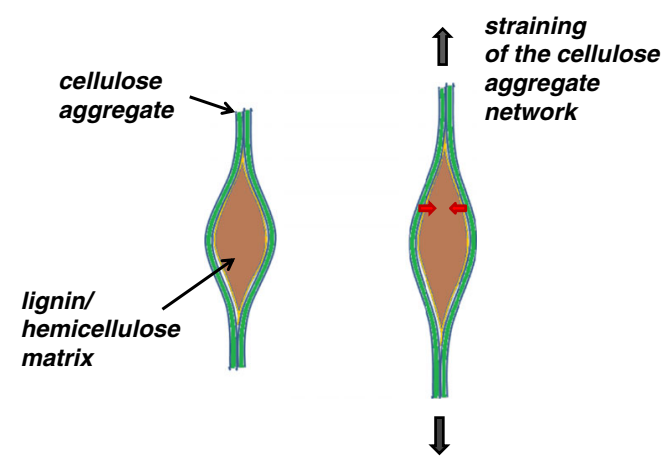

Fig. 8 Cellulose aggregate structure showing the straining of the cellulose aggregate network, indicating the compressive resistance of the lignin/hemicellulose matrix. The elliptical spaces among the cellulose aggregates have a length-to-width ratio of about 2 and a minor diameter across the ellipse of 5 to $10 \mathrm{~nm}$ 
and Wännström 1986). The extent of these bonds could be debated, at least from a polymer point of view, with lignin supposedly showing a glass transition independent of other components (Olsson and Salmén 1997), pointing to a matrix arrangement with lignin and hemicelluloses acting as individual components. With regard to polymeric properties, the ability to act as separate components is based on the ability of the polymer chains to act cooperatively in order to show a behaviour representing that of the isolated material. It is usually estimated that this requires a polymer volume with a diameter of about 5 to $15 \mathrm{~nm}$ (Kaplan 1976), a space that may be considered possible if accounting for the longer direction of the lenticular spaces between the cellulose fibrils. On the other hand, studies suggest that there may well be different types of lignin present in a cell wall (Lawoko et al. 2005; Ruel and Joseleau 2005), see Fig. 1. Consequently, it may well be that one of these fractions could be mixed more intimately with one of the hemicelluloses and therefore possess a common softening point at a lower temperature or moisture content than that which is commonly detected for lignin. Such a joint structure of hemicelluloses and lignin may imply a more cross-linked network stabilising the cell wall assembly.

With such an intermixed structure of wood polymers in a cell wall, it could be assumed that the construction is developed for a maximal utilization of the stress-taking ability of the components so as to be economically most beneficial for the tree structure. So far, studies on a microlevel regarding stress transfer when loading wood fibres have not been able to demonstrate whether lignin makes much of a contribution. Raman and FTIR measurements of stress deformation in lignin have been unsuccessful in detecting a straining of the lignin molecule, even with very high stresses on the cellulose molecules themselves (Gierlinger et al. 2006; Salmén and Bergström 2009). Here, one could make an argument about the suitability of the method itself, i.e. whether the sensitivity of the lignin structure is sufficient enough for stresses on the bonds in the aromatic ring to be even observed. However, when examining a primary wall structure, in which lignin plays a more dominant role in the cell wall organization, straining in the lignin molecule can be seen, as detected with the split in the $1,510 \mathrm{~cm}^{-1}$ vibration in a dynamic FTIRspectrum (Fig. 7) (Salmén and Olsson 2014 unpublished work). Consequently, when the lignin participates in the stress transfer, a straining in the bonds in the aromatic ring structure is clearly evident, although it is not as distinct as that of the cellulose deformations exemplified by the $\mathrm{C}-\mathrm{OH}$ bending deformation at $1,425 \mathrm{~cm}^{-1}$ (Hinterstoisser et al. 2001). The question as to why such a deformation is not observed, when straining the secondary cell wall, may not be easily answered. The undulating structure of the cellulose fibrils/aggregates could be interpreted as a network structure if it is considered that fibrils may act as crosslinks between aggregates. If so, the structure could be interpreted as a honeycomb structure. The lignin/hemicellulose matrix filling the spacing between the cellulose aggregates may more or less then have a function of providing for a compressive resistance during the straining in this honeycomb structure (Fig. 8). The lignin is thus under hydrostatic-like stress, a stress which not necessarily may be detectable by FTIR or Raman spectroscopy.

\section{Conclusions}

It is clearly evident that the secondary cell wall of wood fibres is a highly intermixed composite material, in which the very detailed structure is not yet fully understood. The properties of hemicelluloses and lignin influence transverse fibre properties to a great extent. In addition, the fact that these polymers do not possess isotropic properties in the $\mathrm{S}_{2}$ wall must be taken into consideration. Cellulose is clearly the component of most importance when it comes to affecting cell wall properties. Furthermore, it is evident that accessible zones are mostly arranged in parallel with the cellulose crystalline regions, leading to the very low moisture dependence of cell wall properties. The aggregation and aggregate structures of the cellulose microfibrils have importance for pulp properties and the ability to disintegrate the cell wall structure easily. The fact that lignin is involved in the stress transfer in the cell wall to such a low degree is surprising and a subject that needs to be better understood.

Open Access This article is distributed under the terms of the Creative Commons Attribution License which permits any use, distribution, and reproduction in any medium, provided the original author(s) and the source are credited.

\section{References}

Åkerholm M, Salmén L (2001) Interactions between wood polymers studied by dynamic FT-IR spectroscopy. Polymer 42:963-969

Åkerholm M, Salmén L (2003) The oriented structure of lignin and its viscoelastic properties studied by static and dynamic FT-IR. Holzforschung 57:459-465

Atalla RH, Agarwal UP (1985) Raman microprobe evidence for lignin orientation in the cell walls of native woody tissue. Science 227: 636-639

Atalla RH, Hackney JM, Uhlin I, Thompson NS (1993) Hemicelluloses as structure regulators in the aggregation of native cellulose. Int $\mathrm{J}$ Biol Macromol 15:109-112

Bardage S, Donaldson L, Tokoh C, Daniel G (2004) Ultrastructure of the cell wall of unbeaten Norway spruce pulp fibre surfaces. Nordic Pulp Pap Res J 19:448-452

Bergander A, Salmén L (2000) The transverse elastic modulus of the native wood fibre wall. J Pulp Pap Sci 26:234-238

Bergander A, Salmén L (2002) Cell wall properties and their effects on the mechanical properties of fibers. J Mater Sci 37:151-156

Boyd JD (1982) An anatomical explanation for visco-elastic and mechanosorptive creep in wood, and effects of loading rate on

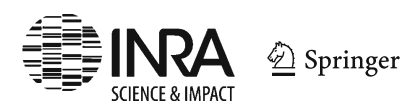


strength. In: Baas P (ed) New perspectives in wood anatomy. Martinus Nijhoff/Dr W Junk, Publishers, La Hague, pp 171-222

Duchesne I, Daniel G (2000) Changes in surface ultrastructure of Norway spruce fibres during kraft pulping — visualisation by field emissionSEM. Nordic Pulp Pap Res J 15:54-61

Duchesne I, Hult E-L, Molin U, Daniel G, Iversen T, Lennholm H (2001) The influence of hemicellulose on fibril aggregation of kraft pulp fibres as revealed by FE-SEM and CP/MAS13C-NMR. Cellulose 8:103-111

Ehrnrooth EML, Kolseth P (1986) Mechanical softening of single wood pulp fibers'. In: Bristow JA, Kolseth P (eds) Paper structure and properties. Marcel Dekker, Inc., New York, pp 27-50

Fahlén J, Salmén L (2003) Cross-sectional structure of the secondary wall of wood fibers as affected by processing. J Mater Sci 38:119-126

Gierlinger N, Schwanninger M, Reinecke A, Burgert I (2006) Molecular changes during tensile deformation of single wood fibers followed by Raman microscopy. Biomacromolecules 7:2077-2081

Hinterstoisser B, Åkerholm M, Salmén L (2001) Effect of fiber orientation in dynamic FTIR study on native cellulose. Carbohydr Res 334: $27-37$

Hult E-L (2001) CP/MAS 13C-NMR spectroscopy applied to structure and interaction studies on wood and pulp fibres. Ph.D. thesis, Pulp and paper chemistry and technology, KTH Royal Institute of Technology, Stockholm

Hult E-L, Larsson PT, Iversen T (2001) Cellulose fibril aggregation - an inherent property of kraft pulps. Polymer 42:3309-3314

Iversen T, Wännström S (1986) Lignin-carbohydrate bonds in a residual lignin isolated from pine kraft pulp. Holzfors 40:19-22

Jurasek L (1998) Molecular modelling of fibre walls. J Pulp Pap Sci 24: 209-212

Kaplan DS (1976) Structure-property relationships in copolymers to composites: Molecular interpretation of the glass transition phenomenon. J Appl Pol Sci 20:2615-2629

Larsson PT, Salmén L (2014) Influence of cellulose supra-molecular structure on strength properties of chemical pulp. Holzforschung Published on-line. DOI 10.1515/hf-2013-0226

Larsson PT, Wickholm K, Iversen TA (1997) CP/MAS 13C NMR investigation of molecular ordering in cellulose. Carbohydr Res 302:19-25

Lawoko M, Henriksson G, Gellerstedt G (2005) Structural differences between the lignin-carbohydrate complexes present in wood and in chemical pulps. Biomacromolecules 6:3467-3473

Mark RE (1967) Cell wall mechanics of tracheids. Yale University Press, New Haven

Molin U (2002) Pulp strength properties - Influence of carbohydrate composition, molar mass and crystalline structure. Ph.D. thesis, KTH Royal Institute of Technology, Stockholm

Olsson A-M, Salmén L (1997) The effect of lignin composition on the viscoelastic properties of wood. Nordic Pulp Pap Res J 12: $140-144$
Olsson A-M, Bjurhager I, Gerber L, Sundberg B, Salmén L (2011) Ultrastructural organisation of cell wall polymers in normal-and tension wood of aspen revealed by polarisation FT-IR microspectroscopy. Planta 233:1277-1286

Page DH (1976) A note on the cell wall structure of softwood tracheids. Wood Fiber 7:246-248

Ruel K, Joseleau J-P (2005) Deposition of hemicelluloses and lignins during secondary wood cell wall assembly. In: Entwistle KM, Walker JCF (eds) The hemicelluloses workshop 2005. University of Canterbury, Christchurch, pp 103-113

Salmén L (2004) Micromechanical understanding of the cell-wall structure. C R Biol 327:873-880

Salmén L (2005) The mechanical deformation of wood - relation to ultrastructure. In: Entwistle KM, Harris P, Walker JCF (eds) The compromised wood workshop 2007. University of Canterbury, Christchurch, pp 143-157

Salmén L, Bergström E (2009) Cellulose structural arrangement in relation to spectral changes in tensile loading FTIR. Cellulose 16:975982

Salmén L, Olsson A-M (2014) Unpublished results. Innventia, Box 5604, SE-11486 Stockholm, Sweden

Salmén L, Olsson A-M, Stevanic J, Simonović J, Radotić K (2012) Structural organisation of the wood polymers in the wood fibre structure. BioResources 7:521-532

Simonović J, Stevanic J, Djikanović D, Salmén L, Radotić K (2011) Anisotropy of cell wall polymers in branches of hardwood and softwood: a polarized FTIR study. Cellulose 18:1433-1440

Stevanic J, Salmén L (2009) Orientation of the wood polymers in spruce wood fibres. Holzforschung 63:497-503i

Terashima N (1990) A new mechanism for formation of a structurally ordered protolignin macromolecule in the cell wall of tree xylem. J Pulp Pap Sci 16:J150-J155

Terashima N, Fukushima K, He L-F, Takabe K (1993) Comprehensive model of the lignified plant cell wall, in Forage Cell Wall Structure and Digestibility. American Society of Agronomy, Madison, Wisc., pp 247-270

Terashima N, Kitano K, Kojima M, Yoshida M, Yamamoto $\mathrm{H}$, Westermark U (2009) Nanostructural assembly of cellulose, hemicellulose and lignin in the middle layer of secondary wall of ginko tracheid. J Wood Sci 55:409-416

Wang N, Liu W, Peng Y (2013) Gradual transition zone between cell wall layers and its influence on wood elastic modulus. J Mater Sci 48: 5071-5084

Wang N, Liu W, Lai J (2014) An attemot to model the influence of gradual transition between cell wall layers on cell wall layers on cell wall hygroelastic properties. J Mater Sci 49:1984-1993

Wickholm K, Larsson PT, Iversen T (1998) Assignment of noncrystalline forms in cellulose I by CP/MAS 13C NMR spectroscopy. Carbohydr Res 312:123-129 